\title{
The Effect of Benson Relaxation Technique on Sleep Quality after Coronary Artery Bypass Graft Surgery
}

\author{
Fatemeh Moradi Mohammadi $^{1}$, Hosein Bagheri ${ }^{2 *}$, Ahmad Khosravi ${ }^{3}$, \\ Malihe Ameri', Mahboobeh Khajeh ${ }^{2}$
}

1. MSc. candidate of Nursing, Student Research Committee, School of Nursing and Midwifery, Shahroud University of Medical Sciences, Shahroud, Iran

2. Ph. D, Assistant professor of Nursing, School of Nursing and Midwifery, Shahroud University of Medical

Sciences, Shahroud, Iran

3. Ph. D, Assistant Professor of Epidemiology, School of Public Health, Shahroud University of Medical Sciences, Shahroud, Iran

4. MSc. in Nursing, School of Nursing and Midwifery, Shahroud University of Medical Sciences, Shahroud, Iran

\section{Article Info}

Received: 2018/07/14;

Accepted: 2018/08/20;

Published Online: 2019/08/28

10.30699/sjhnmf.27.6.386

Original Article

Use your device to scan and read the article online

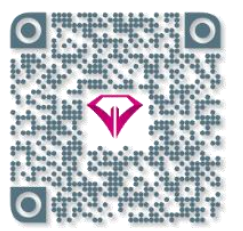

\section{ABSTRACT}

Introduction: One of the common problems of patients after open heart surgery is sleep disturbance. The aim of this study was to investigate the effect of benson relaxation on sleep quality after coronary artery bypass graft.

Methods: In this randomized controlled trial, 80 patients allocated to the benson relaxation and control groups. For the intervention group, Benson's relaxation technique was done twice a day for a period of four weeks. The control group received routine care only. In both groups, sleep quality was measured before and after study using Pittsburgh sleep quality questionnaire. Data was analyzed using SPSS software.

Results: Befor intervention, there were no significant differences between two groups of Benson relaxation and control group in any variables of sleep quality and total sleep quality $(P>0.05)$. After intervention, in the Benson relaxation group, the patients' sleep quality was significantly better than the control group in terms of subjective sleep quality, sleep latency, sleep efficacy, sleep disturbances and total quality $(P<0.05)$. However, there was no significant difference between Benson relaxation and control group in the variables of sleep duration, taking sleep drugs and daily dysfunction $(P>0.05)$.

Conclusion: Using Benson's relaxation technique as supplementary and alternative therapies to improve the sleep quality of patients after open heart surgery is recommended.

Keywords: Benson relaxation technique, Sleep quality, Coronary artery bypass graft surgery

\section{Corresponding Information: \\ Hosein Bagheri, PhD in Nursing, Assistant Professor, Faculty of Nursing and Midwifery, Shahroud University of Medical Sciences, Shahroud, Iran. Email: baghe_h1@yahoo.com}

Copyright $\odot$ 2020, This is an original open-access article distributed under the terms of the Creative Commons Attribution-noncommercial 4.0 International License which permits copy and redistribution of the material just in noncommercial usages with proper citation.

\section{How to Cite This Article:}

Moradi Mohammadi F, Bagheri H, Khosravi A, Ameri M, Khajeh M M. The Effect of Benson Relaxation Technique on Sleep Quality after Coronary Artery Bypass Graft Surgery. Avicenna J Nurs Midwifery care. 2020; 27 (6) :371-380 
بررسى تأثير آرامسازى بنسون بر كيفيت خواب بيماران يس از جراحى پييوند عروق كرونر

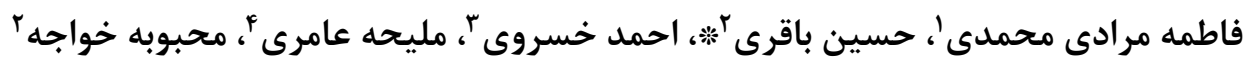

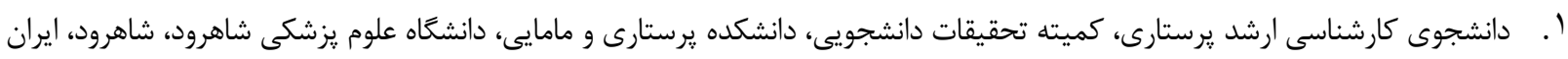

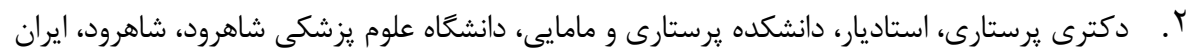

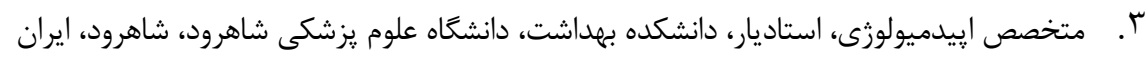

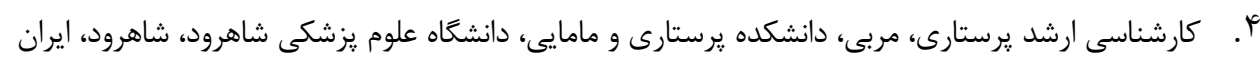

\begin{tabular}{|c|c|}
\hline جكيده & اطلاعات مقاله \\
\hline 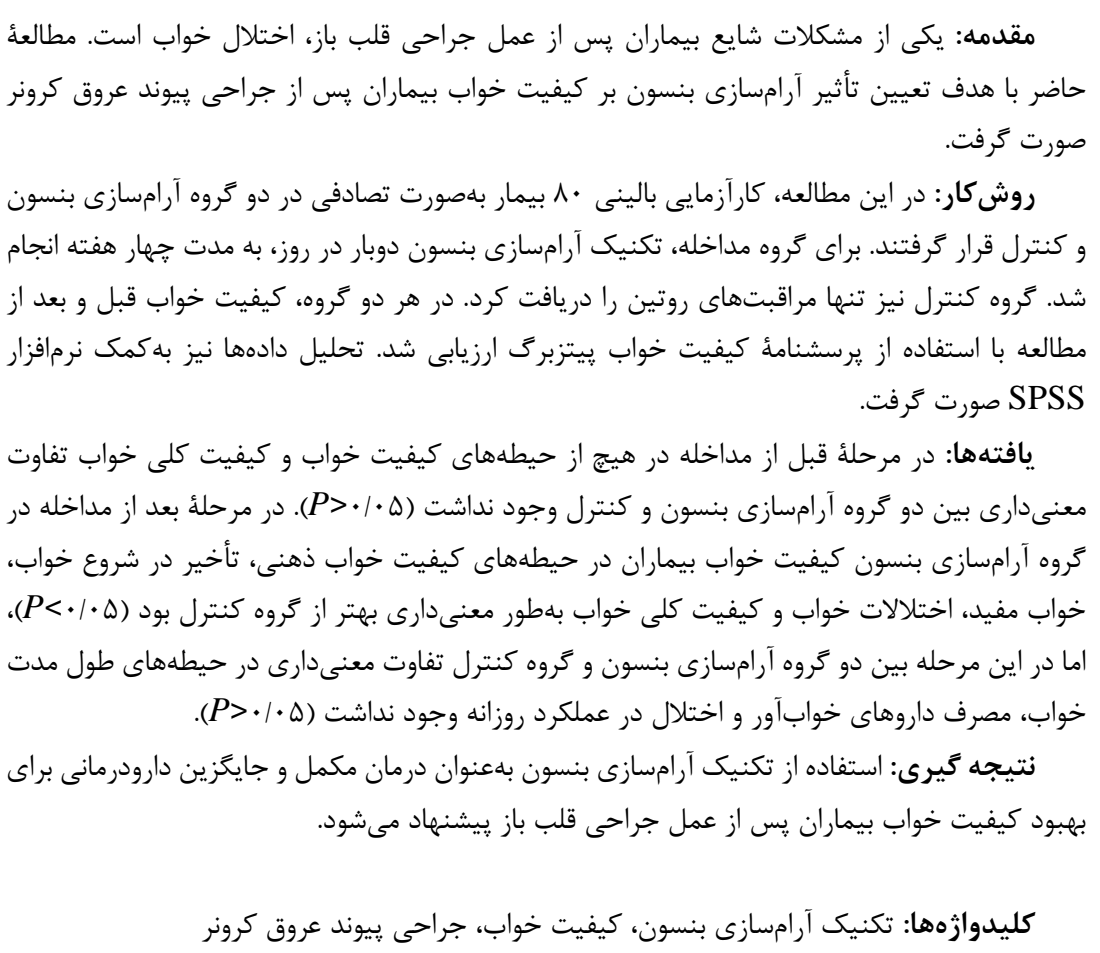 & 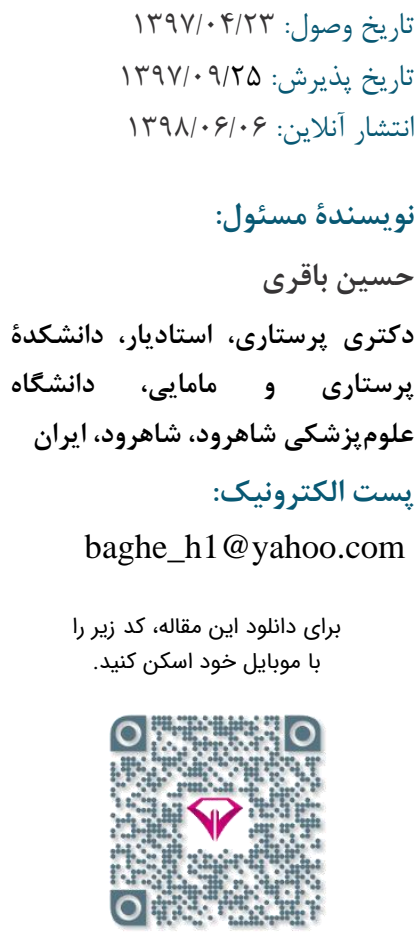 \\
\hline
\end{tabular}

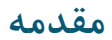

مرگومير، ناتوانى و كارافتادگى بخش وسيعى از نيروهاى

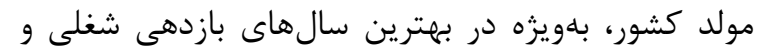

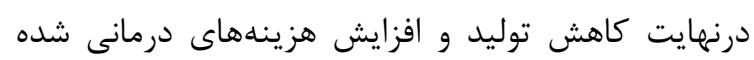

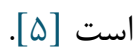

جراحى ييوند عروق كرونر به نحو مطلبى سبب تسكين

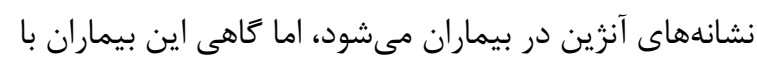

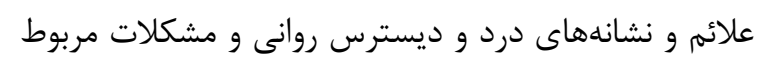

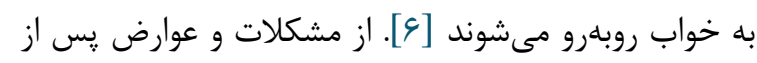
جراحى باى يس عروق كرونر مىتوان به درد محل برش ناحية

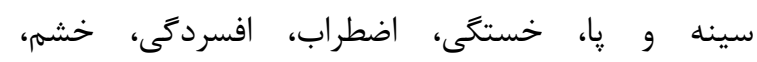

بيمارىهاى قلبى عروقى علت اصلى مرگ در سراسر

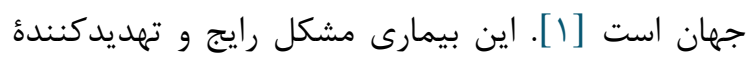
زندكى در كشورهاى توسعهيافته و درحالتوسعه در مردان

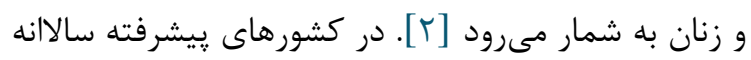

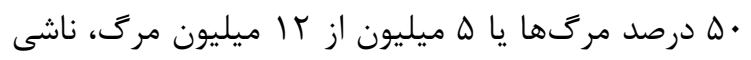

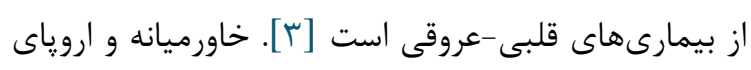
شرقى بالاترين ميزان مرگومير بيمارىهاى قلبى قدى -عروقى

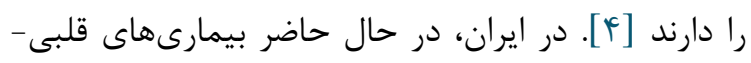

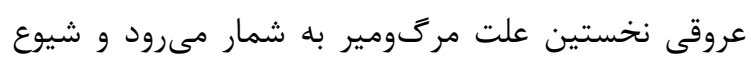

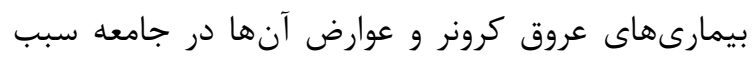


آرامسازى يكى از مداخلات يرستارى است كه در

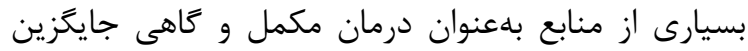

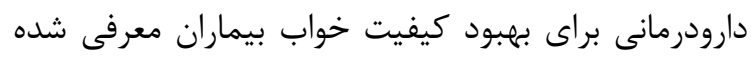

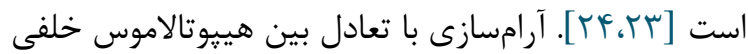
و قدامى، كاهش فعاليت سيستم عصبى سمياتيك و ترشح

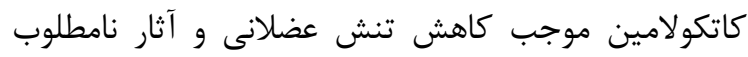

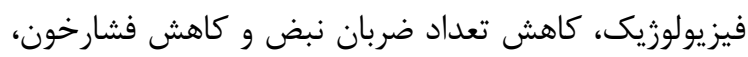
منظم شدن تنفس و اسياسم عضلانى ناشى از استرس

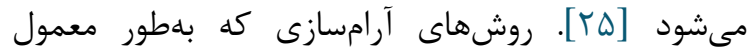

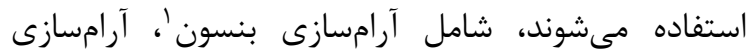

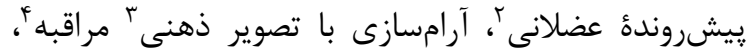

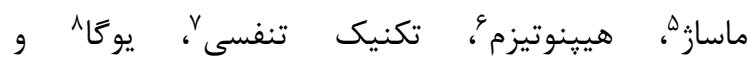

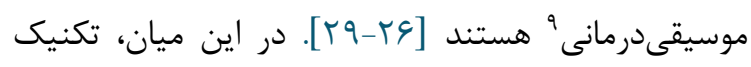
آرامسازى بنسون بهدليل يادكيرى و آموزش آسان آن به آنه ديخران، بيشتر از ساير روشها مدنظر متخصصان درمان قرار

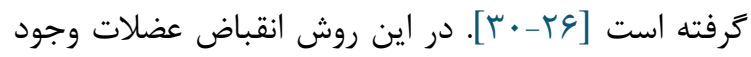
ندارد؛ زيرا موجب افزايش تعداد نبض، تنفس و فشارخون

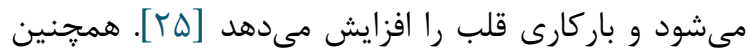
اين تكنيك نيازى به كاركنان تخصصى و وسايل و ابزار ويزه

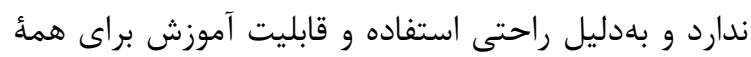

افراد، مدنظر قرار ترفته است [آبـ] تاكنون در جندين مطالعه، اثربخشى تكنيكهاى

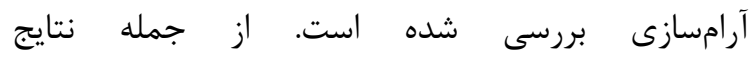

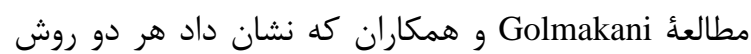
آرامسازى يُشرونده عضلانى و تجسم هدايتشده تأثير مثبتى بر كيفيت خواب زنانى دارد كه براى اولين بار باردار

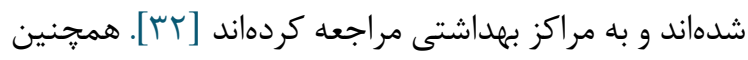
براساس نتايج مطالعه Christina و همكاران، برنامئ تكنيكهاى مديريتى شامل آرامسازى پِيشرونده، تنفس

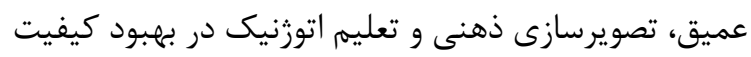

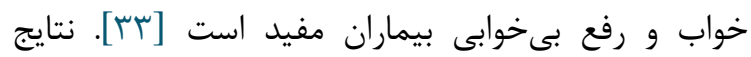

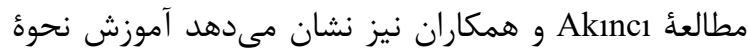

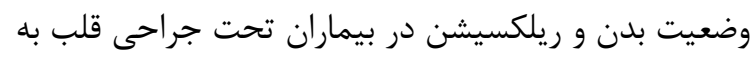

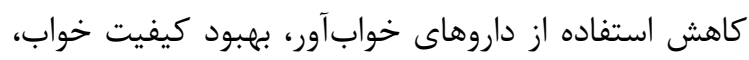
كاهش ديسينه، كاهش درد و بهبود كيفيت زندگى بيماران

\footnotetext{
6. Hypnotise

${ }^{7}$. Breathing Theknic

${ }^{8}$. Yoga

${ }^{9}$. Music Therapy
}

تحريكيذيرى و اختلال خواب اشاره كرد كه بارها از سوى

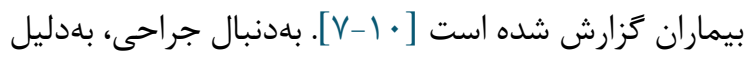

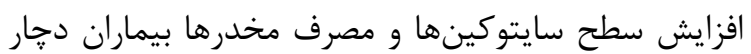

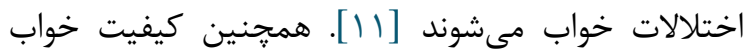
ضعيف در دوره پس از عمل ممكن است بهدليل درد ناحئ

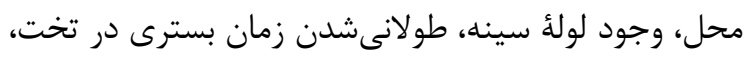

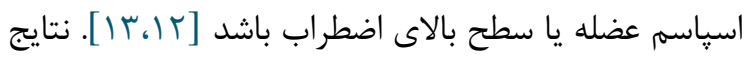

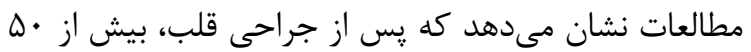

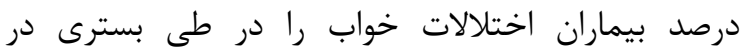

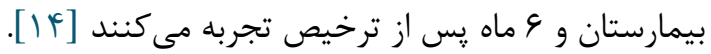
نتايج مطالعهُ اسماعيلى و همكاران نشان داد • • (1-9 هفته يس از عمل جراحى باىيس عروق كرونر كيفيت خواب

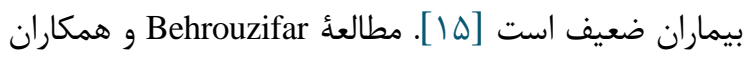

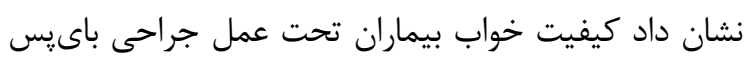

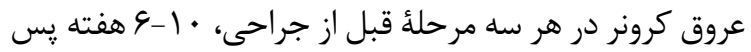

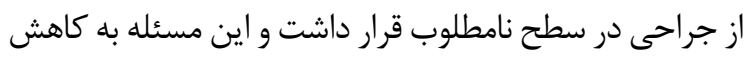
كيفيت زندكى بيماران منجر شده بود [19]. كيفيت خواب

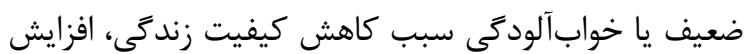

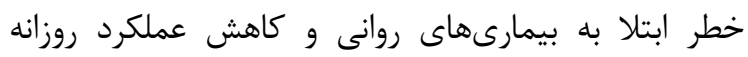

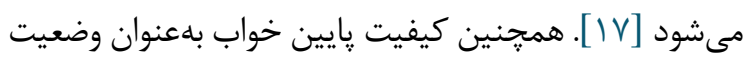
استرسزا ابیىنفرين و نورايىنفرين را ترشح مى كند كه

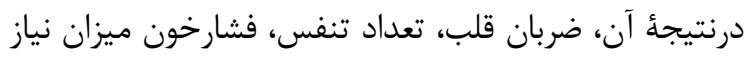

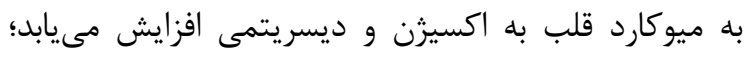

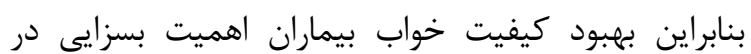
ريكاورى پِ از عمل جراحى باىيس عروق كرونر دارد [11]].

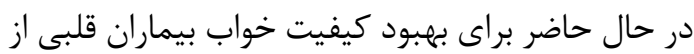

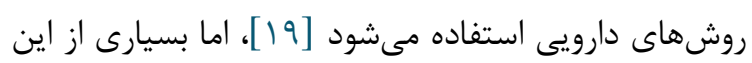
داروهاى خوابآور با بروز برخى عوارض جانبى، مانند ايجاد مقاومت نسبت به اثر دارو و بروز علائم قطع مصرف همراه

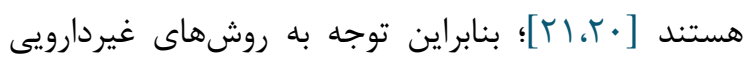

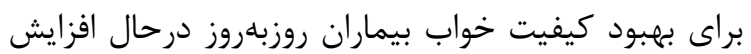

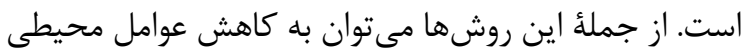
(كاهش صدا، نور و بهبود دماى محيط) و آرامسازى اشاره

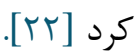


TVF بر برسى تأثير آرامسازى بنسون بر كيفيت خواب بيماران پس از جراحى پيوند عروق كرونر

اقدام مى كند. يس از انتخاب هريك از نمونههاى يزوهش، توضيح هدف مطالعه و كسب رضايت آكاهانهُ كتبى، رئ،

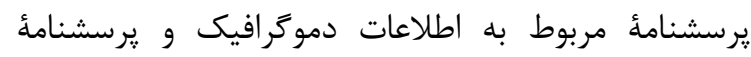

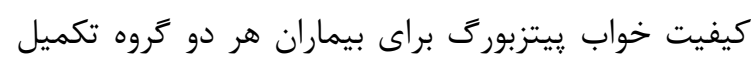

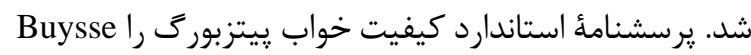

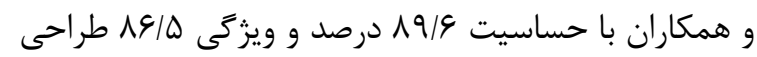

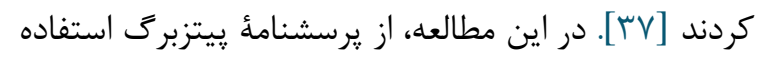

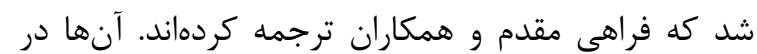

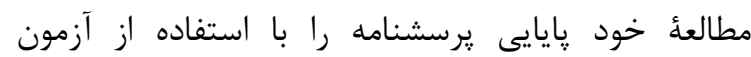

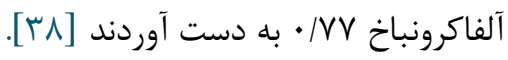

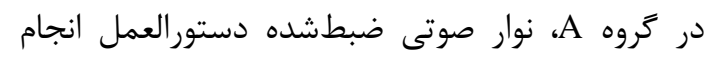

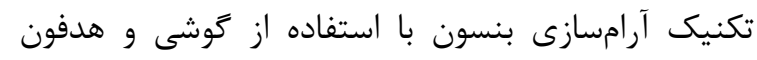

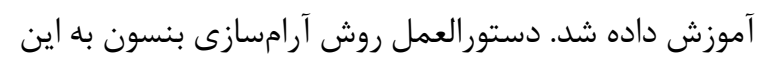

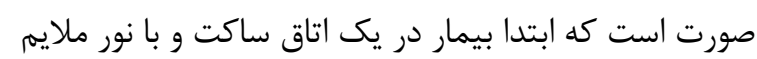
در وضعيت راحت قرار مى كيرد، جشمها را آ آهسته مىبنده،

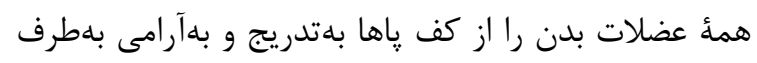

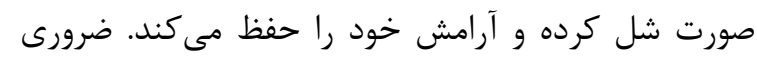

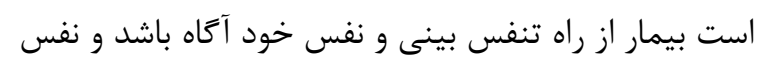

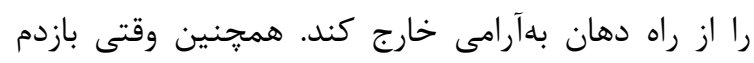

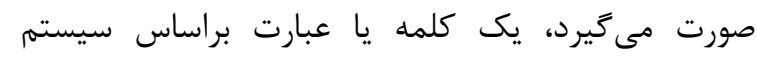

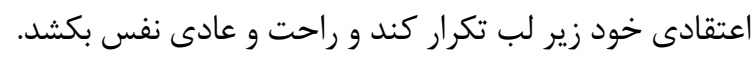

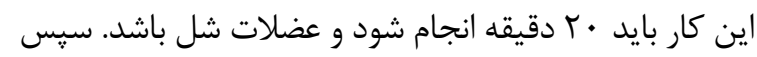

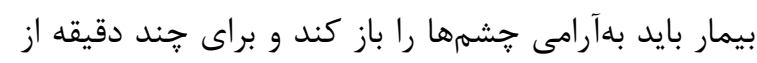

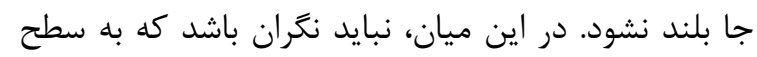

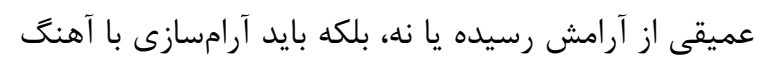

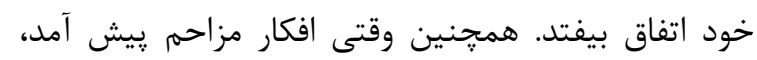

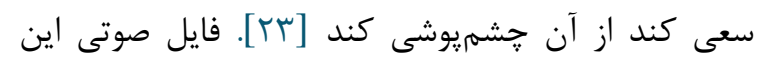

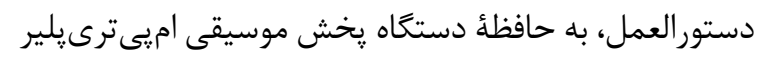

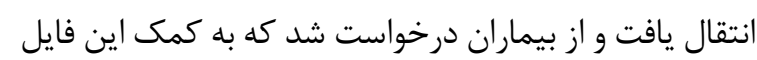

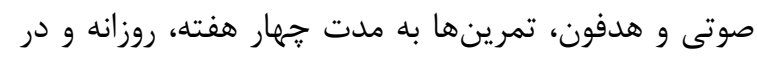

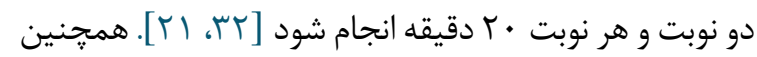

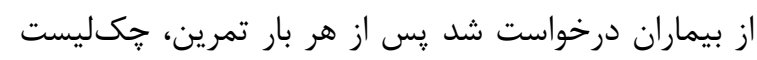

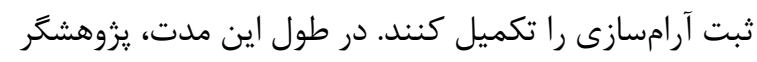

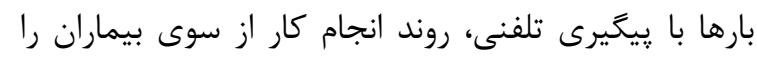

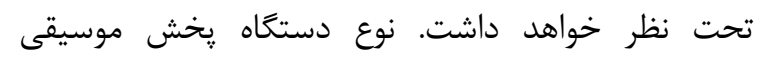
اميىترىيلير و هدفون براى همأ بيماران كَروه مداخله

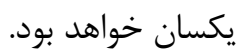

منجر مىشود [1 I I]. براساس نتايج مطالعئ Akbarzadeh و

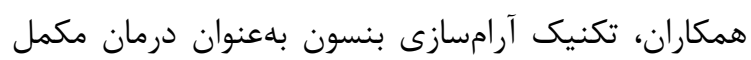

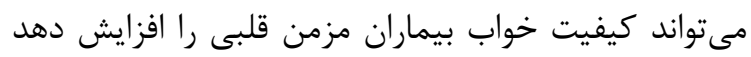

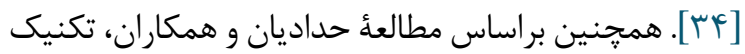

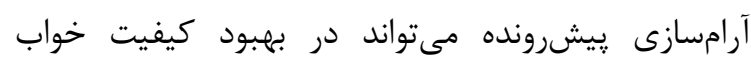

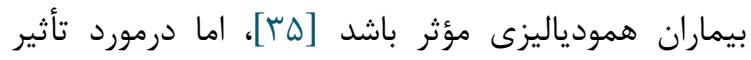

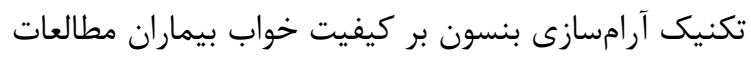

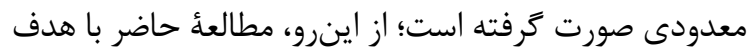

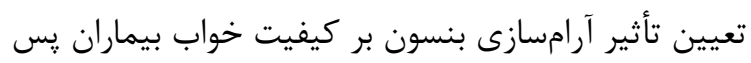
از جراحى ييوند عروق كرونر صورت گرفته است.

$$
\text { روش بررسى }
$$

در يزوهش كارآزمايى بالينى تصادفىشده حاضر

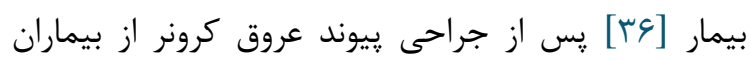

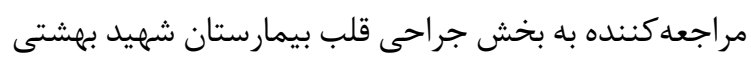
و بيمارستان حضرت وليعصر (عج) قم براساس معيارهاى

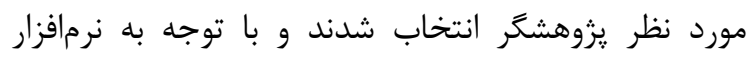

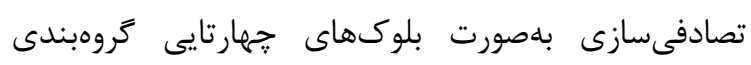

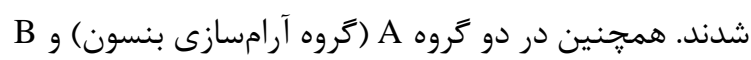

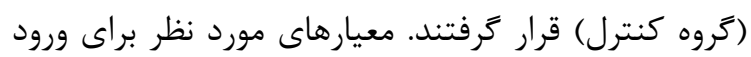
نمونهها به يزوهش حاضر شامل افراد

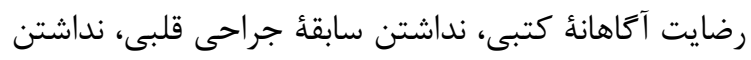

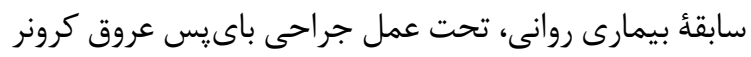

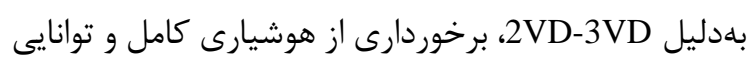

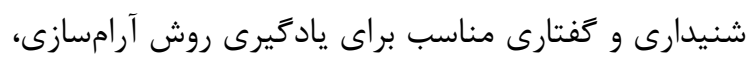

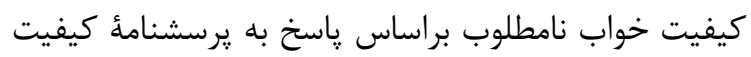

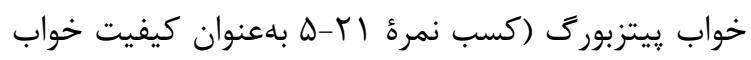

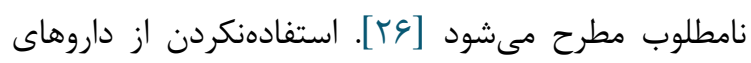

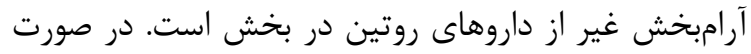

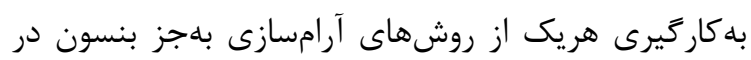

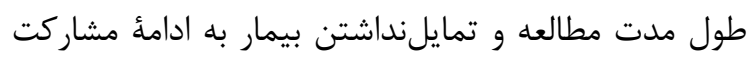

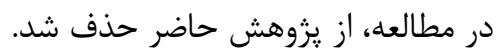

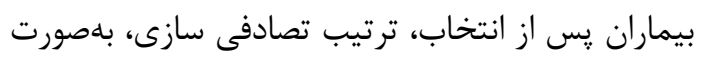

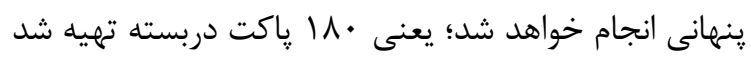

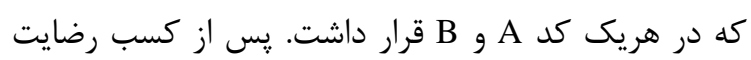

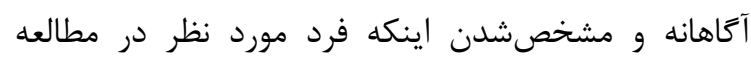

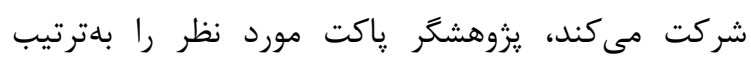

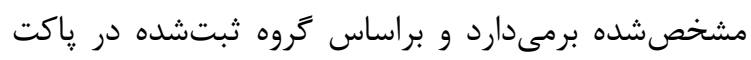


براساس نتايج آزمون كولموكرواسميرنف، دادههاى مربوط به

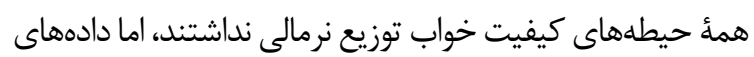

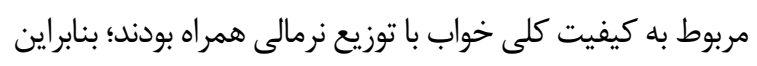

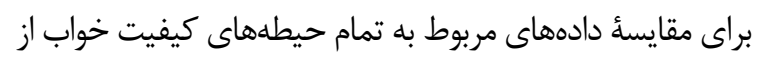

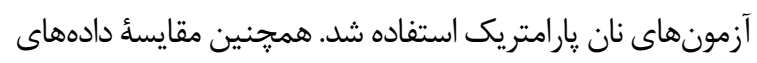

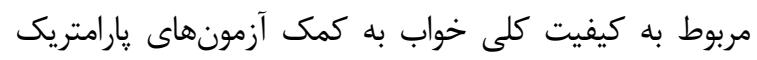

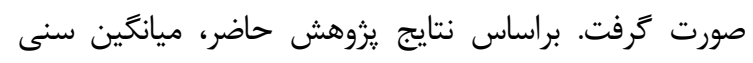

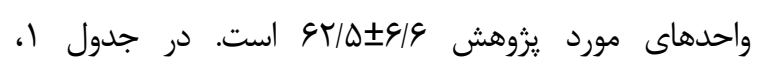

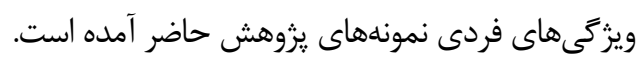

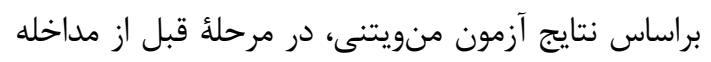

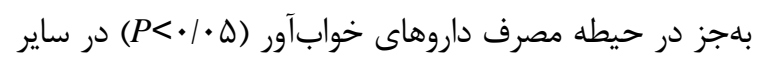

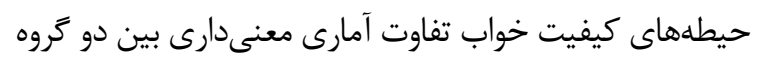

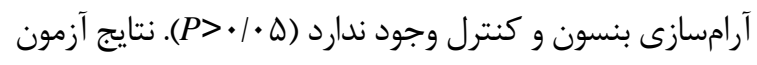

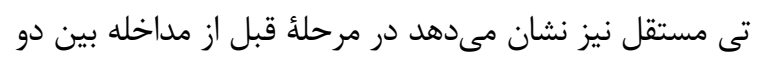

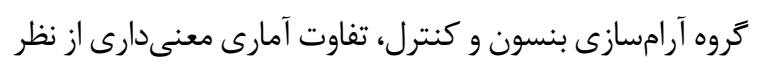

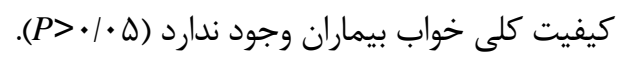

جهار هفته پِ از تمرينهاى آرامسازى، با حضور بيمار

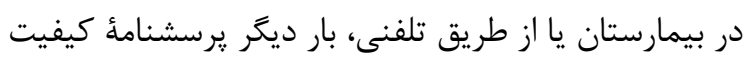

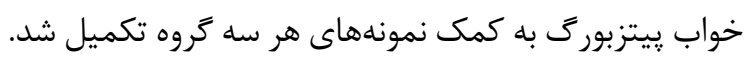

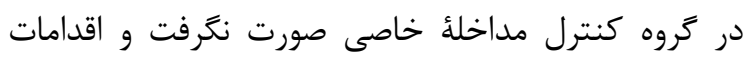

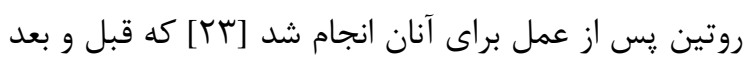

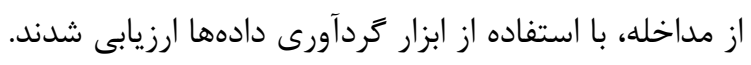

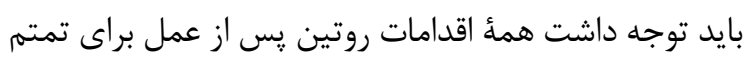

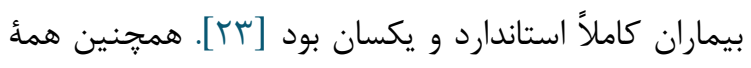

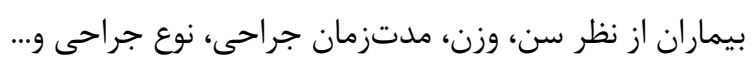

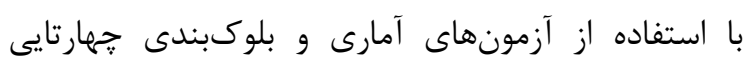

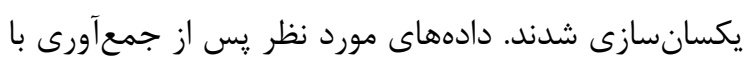

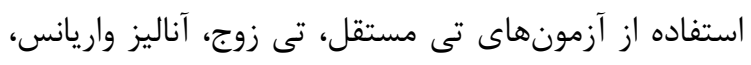

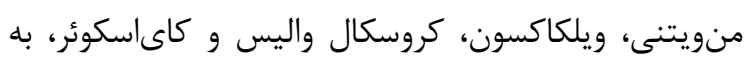

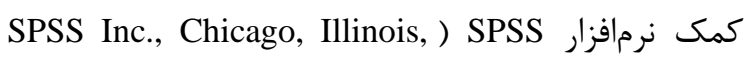

(USA

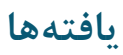

\section{جدول ا. توزيع فراوانى مطلق و نسبى ويزُكىهاى فردى بيماران يُوهش حاضر}

\begin{tabular}{|c|c|c|c|}
\hline درصد & فراوانى & & \\
\hline$r V / \Delta$ & $r$. & كمتر از •4 & \multirow{3}{*}{ سن } \\
\hline$\Delta I / T$ & il & $9 \cdot-99$ & \\
\hline $11 / r$ & 9 & بيشتر از ب & \\
\hline $9 \pi / 1$ & DI & مرد & \multirow{2}{*}{ جنس } \\
\hline rg/T & rq & زن & \\
\hline ANV & VI & زير دييلم & \multirow{3}{*}{ تحصيلات } \\
\hline$\Delta$ & f & دييله & \\
\hline $9 / \pi$ & $\Delta$ & دانشخاهى & \\
\hline$\Lambda T / \Delta$ & 99 & متأهل & \multirow{3}{*}{ وضعيت تأهل } \\
\hline 1915 & ir & بيوه & \\
\hline $1 / r$ & 1 & مطلقه & \\
\hline$\Delta$ & r & كارمند & \multirow{7}{*}{ شغل } \\
\hline$N / \Lambda$ & v & كاركر & \\
\hline $\mid r / \Delta$ & 1. & كشاورز & \\
\hline$r \mid r$ & $r \Delta$ & خانهدار & \\
\hline$r T / \Lambda$ & 19 & آزاد & \\
\hline $\mid r / \Lambda$ & 11 & بازنشسته & \\
\hline$\Delta$ & r & بيكار & \\
\hline$\Delta \Delta$ & fq & كمتر از r & تعداد فرزند \\
\hline
\end{tabular}


rVY بر rVى تأثير آرامسازى بنسون بر كيفيت خواب بيماران پس از جراحى ييوند عروق كرونر

$\begin{array}{ccc}r Y / Q & r-\Delta \\ r / 4 & r & \Delta-j\end{array}$

جدول r. ميانكَين نمرات حيطههاى كيفيت خواب بيماران قبل از مداخله در كروه آرامسازى بنسون و كنترل

\begin{tabular}{|c|c|c|c|c|c|c|}
\hline \multicolumn{2}{|c|}{ آزمون منويتنى } & \multicolumn{2}{|c|}{ كنترل } & \multicolumn{2}{|c|}{ آرامسازى بنسون } & تروه \\
\hline$P$ & $\mathrm{Z}$ & انحراف معيار & ميانكَين & انحراف معيار & ميانكَين & حيطهها \\
\hline$\cdot|r| 1$ & $9 \Lambda \mathrm{r} / \ldots$ & $\cdot / V V$ & $1 / N \Delta$ & $\cdot / V F$ & $1 / \Delta \Delta$ & كيفيت خواب ذهنى \\
\hline . IFVD & $V \pi r / \cdots$ &.$/ 99$ & $1 / \lambda$ &.$/ 9 V$ & $1 / 90$ & تأخير در شروع خواب \\
\hline - /AVT & $\forall \wedge \uparrow / \cdots$ & $1 / \cdot 9$ & I/AD & •/Ar & I/AD & طول مدت خواب \\
\hline 年 & $V T r / \cdots$ & $1 / 19$ & I/AT & $1 / \cdot 9$ & $1 / r$. & خواب مفيد \\
\hline - MFE & $99 \mathrm{~V} / \ldots$ & $\cdot / \Delta \Delta$ & $1 / V T$ & $\cdot / \Delta$ & $1 / \Delta V$. & اختلالات خواب \\
\hline.$/ \cdot 11$ & $9 \Lambda \cdot 1 \ldots$ & $1 / \cdot \cdot$ & $\cdot / 4$ &.$/$. & $\cdot \%$ & مصرف داروهاى خوابآور \\
\hline - par & 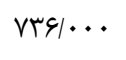 & $\cdot / \Delta \varphi$ & $1 / v$ & r r & $1 / 9$. & اختلال در عملكرد روزانه \\
\hline.$/ 1 Y 4$ & $-1 / \Delta F \Lambda$ & r/G4 & 1.190 & $r / T \Lambda$ & $q / \leftarrow \Delta$ & كيفيت كلى خواب \\
\hline
\end{tabular}

وجود ندارد (ه •/P> (P>). نتايج آزمون تى مستقل نشان مىدهد

براساس نتايج آزمون منويتنى، در مرحلة بعد از مداخله

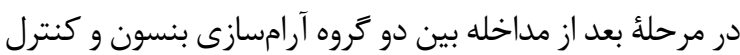

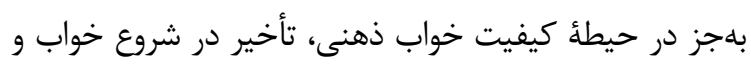

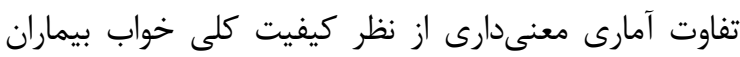

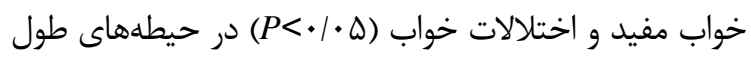

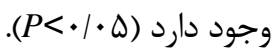

مدت خواب، مصرف داروهاى خوابآور و اختلال عملكرد روزانه تفاوت آمارى معنى دارى بين دو گروه آرامسازى بنسون و كنترل

جدول ب. مقايسهُ ميانغين نمرات حيطههاى كيفيت خواب بيماران بعد از مداخله در تروه آرامسازى بنسون و كروه كنترل

\begin{tabular}{|c|c|c|c|c|c|c|}
\hline \multicolumn{2}{|c|}{ آزمون منويتنى } & \multicolumn{2}{|c|}{ كنترل } & \multicolumn{2}{|c|}{ آرامسازى بنسون } & تروه \\
\hline$P$ & $\mathrm{U}$ & انحراف معيار & ميانكين & انحراف معيار & ميانگين & حيطه ها \\
\hline$\cdot / \cdot r \Delta$ & $919 / 0 \ldots$ & .109 & $1 / F V$ & $\cdot \mid \Delta 9$ & $1 / r$. & كيفيت خواب ذهنى \\
\hline ת & $\Delta \wedge N \cdots$ & $1 / \cdot r$ & $1 / 90$ & . /9T & $1 / 10$ & تأخير در شروع خواب \\
\hline$\cdot / 1 \cdot \Delta$ & s $9 / \Delta .$. & $\mid / T 1$ & I/AT & $1 / 1 f$ & $1 / \pi v$ & طول مدت خواب \\
\hline $.1 \cdot 19$ & $\Delta G \cdot 1 \cdot \cdots$ & $1 / \pi r$ & $1 / 9$. & $1 / 1$. & $\cdot / 90$ & خواب مفيد \\
\hline$\cdot / \cdot \uparrow \Lambda$ & $901 / \cdots$ & $\cdot / \& \Delta$ & $1 / T V$ & $\cdot|q|$ & $1 / \cdot V$ & اختلالات خواب \\
\hline$\cdot 11 \cdot 1$ & $9 \Delta \varepsilon / \ldots$ & $1 / \Gamma \Delta$ & $1 / \cdot \Delta$ & r & $\cdot / \Delta \Delta$ & مصرف داروهاى خوابآور \\
\hline .1995 & $\vee ৭ \Delta / \Delta \cdots$ & $\cdot / V \Delta$ & $1 / 1 T$ & $\cdot / V G$ & $1 / 10$ & اختلال در عملكرد روزانه \\
\hline$\cdot / \cdot r$ & $-r / 9 T V$ & $f / 19$ & १/^V & r T & $V / T V$ & كيفيت كلى خواب \\
\hline
\end{tabular}

جدول F. مقايسةُ تفاضل ميانكَين كيفيت كلى خواب قبل و پِ از مداخله در كروه آرامسازى بنسون و كروه كنترل

\begin{tabular}{|c|c|c|c|c|c|}
\hline آزمون من ويتن & \multicolumn{2}{|c|}{ كروه كنترل } & \multicolumn{2}{|c|}{ تروه آرامسازى بنسون } & تروه \\
\hline$P$ & انحراف معيار & ميانكين & انحراف معيار & ميانگين & 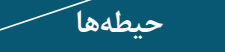 \\
\hline \multirow{3}{*}{$P>\cdot / \cdot \Delta$} & $\cdot|V|$ & $-\cdot / T V$ & .194 & $-\cdot / r \Delta$ & كيفيت خواب ذهنى \\
\hline & $1 / \cdot r$ & $-\cdot / 10$ & $1 / \cdot 1$ & $-\cdot / \Delta \cdot$ & تأخير در شروع خواب \\
\hline & $1 / \cdot r$ & $-\cdot / \cdot r$ & $1 / \cdot 1$ & $-\cdot / 4 V$ & طول مدت خواب \\
\hline
\end{tabular}




\begin{tabular}{|c|c|c|c|c|c|}
\hline آزمون من ويتن & \multicolumn{2}{|c|}{ كروه كنترل } & \multicolumn{2}{|c|}{ كروه آرامسازى بنسون } & 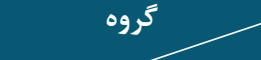 \\
\hline$P$ & انحراف معيار & ميانگين & انحراف معيار & ميانگين & Lad \\
\hline & $1 / \Gamma \omega$ & $-\cdot / 1 V$ & $1 / \Delta \Lambda$ & $-\cdot / r \Delta$ & خواب مفيد \\
\hline & $\cdot / \mathrm{VI}$ & $-\cdot / \& \Delta$ & $\cdot / \Delta \Delta$ & $-\cdot / 0$ & اختلالات خواب \\
\hline & $1 / \pi$ & $\cdot 190$ & $1 / r$ & $\cdot \mid \Delta \Delta$ & مصرف داروهاى خوابآور \\
\hline & $\cdot 19$ & $-\cdot / \Delta \mathrm{V}$ & $\cdot / \wedge V$ & $-\cdot / \mathbb{F} \Delta$ & اختلال در عملكرد روزانه \\
\hline & $r / \mathcal{R}$. & $\cdot / V V$ & r/V & $r / \cdot V$ & كيفيت كلى خواب \\
\hline
\end{tabular}

نتايج مطالعة Rambod و همكاران نشان مى مدهد استفاده

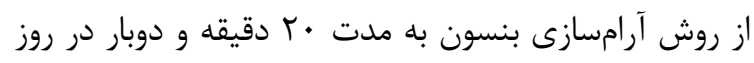
طى دو ماه منجر به بهبود تمام حيطههاى كيفيت خواب

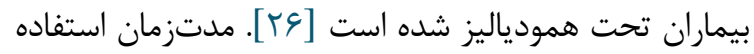

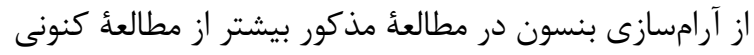
است (دو ماه در برابر يك ماه). بايد توجه داشت استفاده طولانىمدت روشهاى غيردارويى تأثير بهترى بر كيفيت ناه داهن

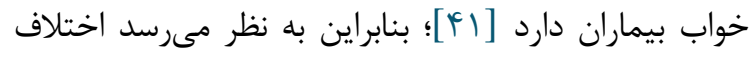

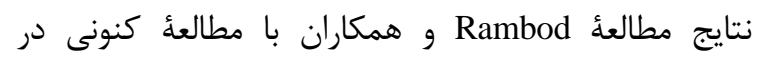
حيطههاى مصرف داروهاى خوابآور و اختلال در عملكرد روزانه مىتواند با تفاوت در مدتزمان استفاده از روش آرامسازى بنسون مرتبط باشد. دربارة تأثير ساير تكنيكهاى آرامسازى مىتونوان به نتايج باندان مطالعة Saeedi و همكاران اشاره كرد. براساس اين مطالعه، استفاده از آرامسازى ييشرونده عضلانى دو بار در روز طى مانى

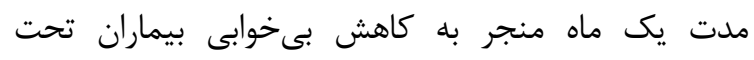

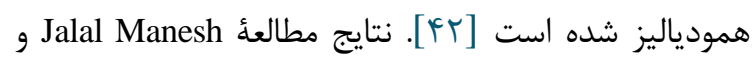
Zargarani عضلانى دو بار در روز طى •له روز منجر به به بهبود تمام

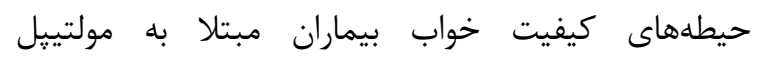

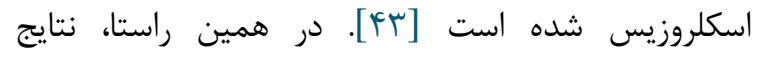
مطالعُ مayapoğlu و همكاران نشان مى مهدد استفاده از

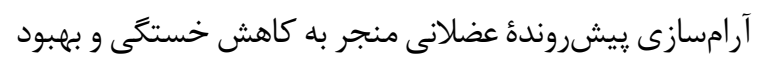
تمام حيطههاى كيفيت خواب بيماران مبتلا به مولتييل

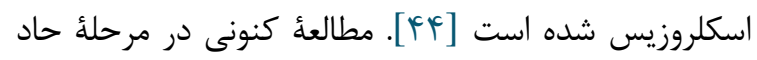
بيمارى (بلافاصله يس از ترخيص بعد از عمل جراحى قلب باز )

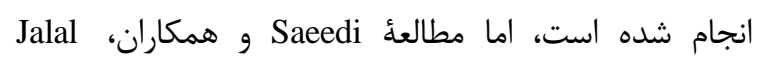
و Manesh و و همكاران بر و Dargapoğlu بيماران مزمن انجام شده است. بيماران حاد كمتر از بيماران
يزوهش حاضر با هدف تعيين تأثير آرامسازى بنسون بر

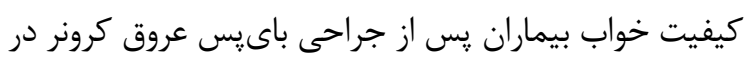

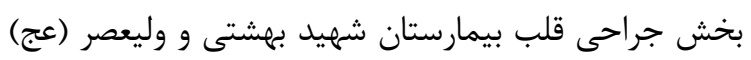

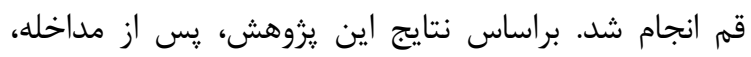

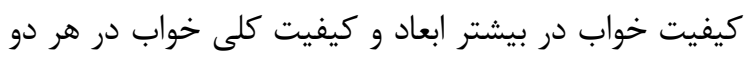

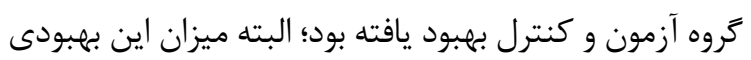

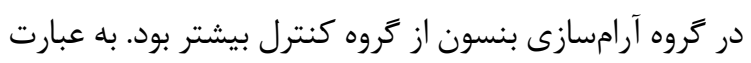

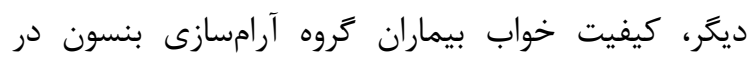
حيطههاى كيفيت خواب ذهنى، تأخير در شروع خواب، خواب

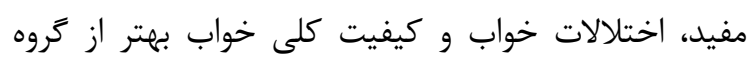

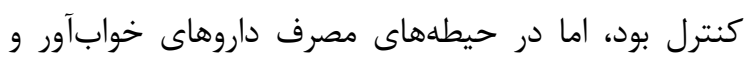

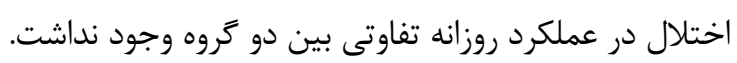

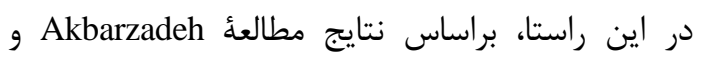

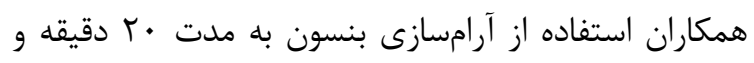
دوبار در روز طى يك ماه منجر به بهبود تمام حيطههاى

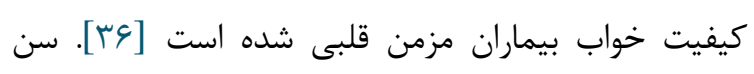

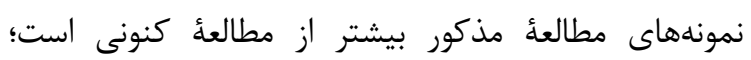

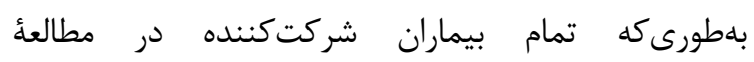
GV/D كمتر از •9kbarzadeh درصد بيماران اين مطالعه بيش از • • سال داشتند. بايد توجه داشت كه با افزايش سن كيفيت خواب بيماران كاهش مي ميابد

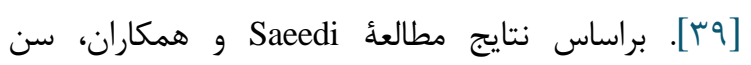
واحدهاى يزوهش همبستخى مستقيم و معنى دارى با نمرهٔ

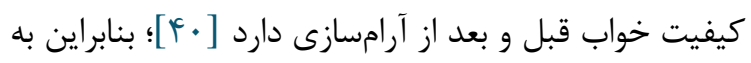
نظر مىرسد مطابقتنداشتن نتايج مطالعهُ اكبرزاده با مطالعه كنونى در حيطههاى مصرف داروهاى خوابآور و اختلال در مر مئن

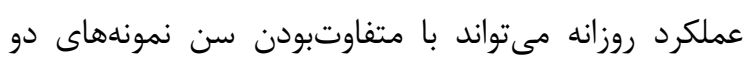
مطالعه مرتبط باشد. 
TVA بررسى تأثير آرامسازى بنسون بر كيفيت خواب بيماران پس از جراحى پيوند عروق كرونر

نسبتاً كم، از محدوديتهاى يزوهش حاضر است كه نيازمند

مطالعات بعدى با حجم نمونه بيشتر در اين زمينه است.

\section{نتيجه}

براساس نتايج يزوهش حاضر، آرامسازى بنسون مىتواند

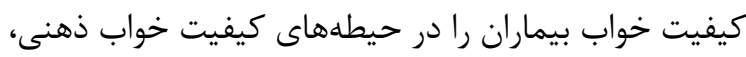
تأخير در شروع خواب، خواب مفيد، اختلالات خواب و كيفيت كلى خواب بهبود بخشد؛ بنابراين استفاده از تكنيك درات آرامسازى بنسون بهعنوان روش مكمل در كنار دارودرمانى بنى بنائ

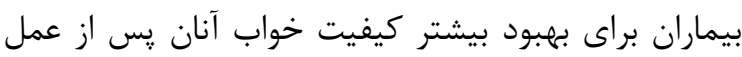

$$
\text { جراحى قلب باز ييشنهاد مىشود. }
$$

\section{سياسگزارى}

يزوهش حاصل بخشى از پاياننامه مقطع كارشناسى

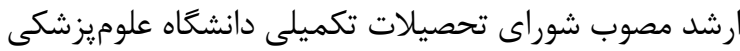
شاهرود در سال هوبا است كه با رعايت حق مؤلفان و

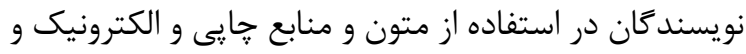
تصويب طرح تحقيقاتى در كميتهٔ اخلاق دانشكاه با كد اخلاق IR.SHMU.REC.1396.163 شاهرود صورت گرفته و در سامانه بالينى با كد داه IRCT201703123064N6 ثبت شده است. بدينوسيله مراتب قدردانى و سياس خويش را از حمايت مالى اين دانشكاه در اجراى اين طرح يزوهشى و همجنين از همكارى

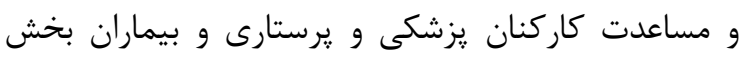

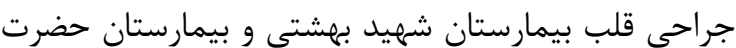

$$
\text { وليعصر (عج) قم ابراز مى كنيم. }
$$

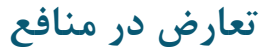

بين نويسندًان هيجَّونه تعارضى در منافع وجود ندارد

$$
\text { منابع مالى }
$$

منابع مالى اين مطالعه توسط نويسندكان تامين شده است.

\section{References}

1. Naseri M. Effect of foot reflexology massage on pain in patients undergoing coronary bypass surgery.

Anesthesiology and Pain. 2015 Jul 15;6(2):42-9.

2. Mendis S, Chestnov O. The global burden of cardiovascular diseases: a challenge to improve. Current
مزمن مىتوانند در برنامههاى بهبود كيفيت خواب خود شركت

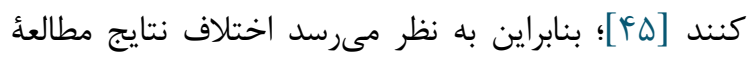

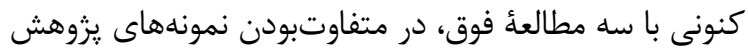
مرتبط باشد. همجنين براساس مطالعهُ Parsa Yekta و همكاران، تأثير

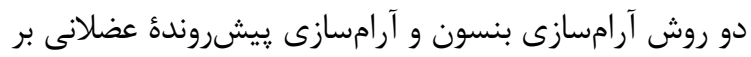
اضطراب بيماران يس از عمل جراحى ماستكتومى بررسى شده ارنه

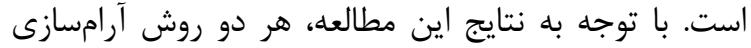

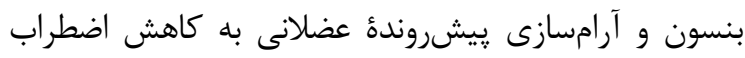
بيماران منجر شده است. براساس نتايج اين مطالعه ميزان كاهش اضطراب كل و اضطراب شناختى بيماران هر دو كروه مشابه است، اما روش آرامسازى بنسون در مقايسه با آرامسازى קيشرونده عضلانى به كاهش بيشتر اضطراب اجتماعى إنى

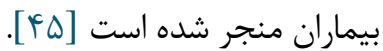
براساس نتايج مطالعة حاضر، بهببود كيفيت خواب در كروه مداخله از كروه كنترل بهتر است، اما ميزان مصرف داروهاى

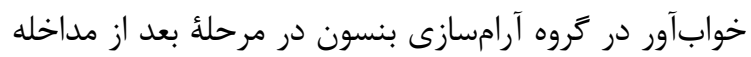

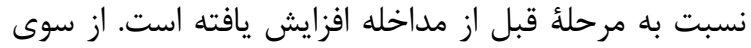
ديكر، ميزان تفاضل ميانخين نمرءٔ همأ حيطههاى كيفيت

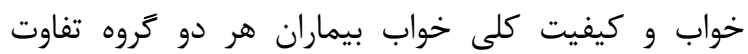

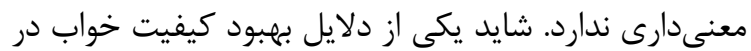
كروه كنترل در بخش جراحى قلب باز اين باشد كه در بخش الش الش

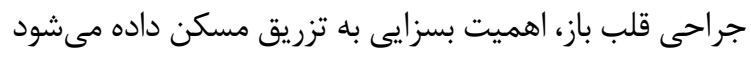
[FV] بيماران بلهورت مداوم از داروهاى مسكن استفاده مىشود

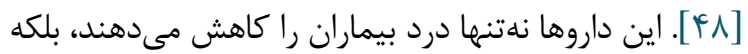

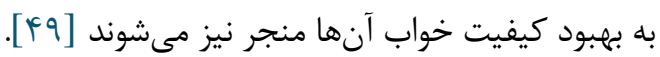

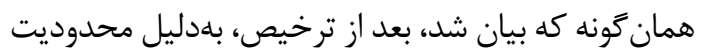
دسترسى بيماران به داروهاى مسكن قوى مانند مخدر •هـ]

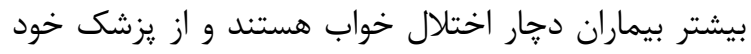

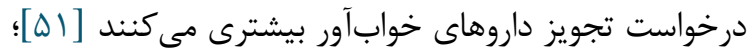
بنابراين مصرف بيشتر داروهاى خوابآور در مرحلة بعد از دراز

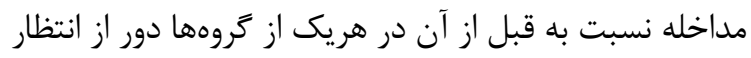
نيست. صرفنظر از نتايج مثبت يزوهش حاضر، حجم نمونهُ

cardiology reports. 2014 May 1;16(5):486.

[DOI:10.1007/s11886-014-0486-3] [PMID]

3. Bahramnezhad F, Mohammadi Y, Asadi A, Seif H, Amini M, Shahbazi B. Comparative study on quality of life in patients after percutaneous transluminal coronary 
angioplasty and coronary artery bypass graft surgery. Iranian Journal of Cardiovascular Nursing 2012; 1 (2).

4. Sarrafzadegan N, Sadeghi M, Oveisgharan S, Iranipour R. Incidence of cardiovascular diseases in an Iranian population: the Isfahan Cohort Study. Archives of Iranian medicine. 2013 Mar 1;16(3):138.

5. Comparative urban and rural patients quality of life after coronary artery bypass surgery.

6. Ardabili FM, Abdi S, Ghezeljeh TN, Fatemeh A, Hosseini AT. Evaluation of the effects of patient-selected music therapy on the sleep quality and pain intensity of burn patients.

7. Özer N, Özlü ZK, Arslan S, Günes N. Effect of music on postoperative pain and physiologic parameters of patients after open heart surgery. Pain Management Nursing. 2013

Mar 1;14(1):20-8. [DOI:10.1016/j.pmn.2010.05.002]

$$
\text { [PMID] }
$$

8. Tully PJ, Baker RA. Depression, anxiety, and cardiac morbidity outcomes after coronary artery bypass surgery: a contemporary and practical review. Journal of geriatric cardiology: JGC. 2012 Jun;9(2):197.

[DOI:10.3724/SP.J.1263.2011.12221] [PMID] [PMCID]

9. Hosseinian A, Kasayi V, Mohammadzade A, Habibzadeh

S, Saghi F, Davari M, Barzegar A, Seyedjavadi M.

Evaluation of early complications of coronary artery bypass grafting surgery (CABGS) in the first month after operation in Imam Khomeini Hospital of Ardabil During 2013-2014. Journal of Ardabil University of Medical Sciences. 2014 Apr 10;14(1):18-27.

10. Akbari M, Celik SS. The effects of discharge training and counseling on post-discharge problems in patients undergoing coronary artery bypass graft surgery. Iranian journal of nursing and midwifery research. 2015 Jul;20(4):442. [DOI:10.4103/1735-9066.161007] [PMID] [PMCID]

11. Nerbass FB, Feltrim MI, Souza SA, Ykeda DS, LorenziFilho G. Effects of massage therapy on sleep quality after coronary artery bypass graft surgery. Clinics. 2010;65(11):1105-10. [DOI:10.1590/S180759322010001100008] [PMID] [PMCID]

12. Akıncı B, Yeldan İ, Bayramoğlu Z, Akpınar TB. The effects of posture and relaxation training on sleep, dyspnea, pain and, quality of life in the short-term after cardiac surgery: a pilot study.

13. Ranjbaran S, Dehdari T, Sadeghniiat-Haghighi K, Majdabadi MM. Poor sleep quality in patients after coronary artery bypass graft surgery: An intervention study using the PRECEDE-PROCEED model. The Journal of

Tehran University Heart Center. 2015;10(1):1. [DOI:10.18869/acadpub.mcs.1.2.99]

14. Liao WC, Huang CY, Huang TY, Hwang SL. A systematic review of sleep patterns and factors that disturb sleep after

heart surgery. Journal of Nursing Research. 2011 Dec 1;19(4):275-88. [DOI:10.1097/JNR.0b013e318236cf68] [PMID]

15. Panagopoulou E, Montgomery A, Benos A. Quality of life after coronary artery bypass grafting: evaluating the influence of preoperative physical and psychosocial functioning. Journal of psychosomatic research. 2006 Jun 1;60(6):639-44. [DOI:10.1016/j.jpsychores.2005.11.004]

$$
\text { [PMID] }
$$

16. Behrouzifar S, Zonouzi SH, Nezafati MH, Esmaeili HA The relationship between sleep patterns and the quality of life in coronary artery bypass graft patients.

17. Harrington JJ, Avidan AY. Treatment of sleep disorders in elderly patients. Current treatment options in neurology.
2005 Oct 1;7(5):339-52. [DOI:10.1007/s11940-005-0027-

$$
\text { x] [PMID] }
$$

18. Kozick C. What nurses need to know about sleep. Colorado nurse (1985). 2013 Nov;113(4):4-.

19. Shafiei Z, Babaee S, Nazari A. The Effectiveness of massage therapy on depression, anxiety and stress of patients after coronary artery bypass graft surgery.

20. Fismer KL, Pilkington K. Lavender and sleep: A systematic review of the evidence. European Journal of Integrative Medicine. 2012 Dec 1;4(4):e436-47. [DOI:10.1016/j.eujim.2012.08.001]

21. Hu RF, Jiang XY, Chen J, Zeng Z, Chen XY, Li Y, Huining $X$, Evans DJ, Wang S. Non-pharmacological interventions for sleep promotion in the intensive care unit. Cochrane Database of Systematic Reviews. 2015(10). [DOI:10.1002/14651858.CD008808.pub2] [PMCID]

22. Montgomery P, Dennis J. A systematic review of nonpharmacological therapies for sleep problems in later life. Sleep medicine reviews. 2004 Feb 1;8(1):47-62. [DOI:10.1016/S1087-0792(03)00026-1]

23. Volpato E, Banfi P, Rogers SM, Pagnini F. Relaxation techniques for people with chronic obstructive pulmonary disease: a systematic review and a meta-analysis. Evidence-Based Complementary and Alternative Medicine. 2015;2015. [DOI:10.1155/2015/628365] [PMID] [PMCID]

24. Xie LQ, Deng YL, Zhang JP, Richmond CJ, Tang Y, Zhou $J$. Effects of progressive muscle relaxation intervention in extremity fracture surgery patients. Western journal of nursing research. $2016 \mathrm{Feb} ; 38(2): 155-68$. [DOI:10.1177/0193945914551509] [PMID]

25. Malmir M, Teimouri F, Pishgooie A, Dabaghi P. The Role of Benson's relaxation on reducing state anxiety on candidate of open heart surgery patient's. Military Caring Sciences Journal. 2015 Dec 15;2(3):182-90. [DOI:10.18869/acadpub.mcs.2.3.182]

26. Rambod M, Pourali-Mohammadi N, Pasyar N, Rafii F, Sharif F. The effect of Benson's relaxation technique on the quality of sleep of Iranian hemodialysis patients: a randomized trial. Complementary therapies in medicine. 2013 Dec 1;21(6):577-84.

[DOI:10.1016/j.ctim.2013.08.009] [PMID]

27. Patel MP. A study to assess the effectiveness of progressive muscle relaxation therapy on stress among staff nurses working in selected hospitals at Vadodara

City. IOSR Journal of Nursing and Health Science.

2014;3(3):34-59. [DOI:10.9790/1959-03323459]

28. Nooner AK, Dwyer K, DeShea L, Yeo TP. Using Relaxation and Guided Imagery to Address Pain, Fatigue, and Sleep Disturbances: A Pilot Study. Clinical journal of oncology nursing. 2016 Oct 1;20(5).

[DOI:10.1188/16.CJON.547-552] [PMID]

29. Nejad SA, Sadat F, Golmakani N, Shakeri MT. Effect of progressive muscle relaxation on depression, anxiety, and stress of primigravid women. Evidence based care. 2015;5(1):67-76.

30. Bikmoradi A, Zafari A, Oshvandi K, Mazdeh M, Roshanaei G. Effect of progressive muscle relaxation on severity of pain in patients with multiple sclerosis: a randomized controlled trial. Journal of hayat. $2014 \mathrm{Apr}$ 15;20(1):26-37.

31. Solehati T, Rustina Y. Benson relaxation technique in reducing pain intensity in women after cesarean section. Anesthesiology and pain medicine. 2015 Jun;5(3). [DOI:10.5812/aapm.22236v2] [PMID] [PMCID]

32. Golmakani N, Nejad SA, Sadat F, Shakeri MT, Asghari Pour N. Comparing the Effects of Progressive Muscle 


$$
\text { •^ץ بررسى تأثير آرامسازى بنسون بر كيفيت خواب بيماران پِ از جراحى پيوند عروق كرونر }
$$

Relaxation and Guided Imagery on sleep quality in primigravida women referring to Mashhad health care centers-1393. Journal of Midwifery and Reproductive Health. 2015;3(2):335-42.

33. Christina D, Panagiotis K, Liza V, George CP. Stress Management for the Treatment of Sleep Disorders in Lawyers: Pilot Experimental Study in Athens, Hellas. Journal of Sleep Disorders: Treatment and Care 2016; 2016.

34. Akbarzadeh R, Koushan M, Rakhshani Mh, Hashemi Ns. Effect Of The Benson Relaxation Technique On Quality Of Sleep In Patients With Chronic Heart Disease.

35. Effect of progressive muscle relaxation technique on sleep quality in hemodialisis patients in kermanshah 2011

36. Akbarzadeh R, Koushan M, Rakhshani Mh, Hashemi Ns. Effect Of The Benson Relaxation Technique On Quality Of Sleep In Patients With Chronic Heart Disease.

37. Buysse DJ, Reynolds CF, Monk TH, Berman SR, Kupfer DJ. The Pittsburgh Sleep Quality Index: a new instrument for psychiatric practice and research. Psychiatry res. 1989 May 1;28(2):193-213. [DOI:10.1016/01651781(89)90047-4]

38. Moghaddam JF, Nakhaee N, Sheibani V, Garrusi B, Amirkafi A. Reliability and validity of the Persian version of the Pittsburgh Sleep Quality Index (PSQI-P). Sleep and Breathing. 2012 Mar 1;16(1):79-82. [DOI:10.1007/s11325-010-0478-5] [PMID]

39. MacLeod S, Musich S, Kraemer S, Wicker E. Practical non-pharmacological intervention approaches for sleep problems among older adults. Geriatric Nursing. 2018 Sep 1;39(5):506-12. [DOI:10.1016/j.gerinurse.2018.02.002]

$$
\text { [PMID] }
$$

40. Saeedi M, Ashktorab T, Saatchi K, Zayeri F, Amir Ali Akbari S. The effect of progressive muscle relaxation on sleep quality of patients undergoing hemodialysis. Iranian Journal of Critical Care Nursing. 2012 Jan 1;5(1):23-8.

41. Blanaru M, Bloch B, Vadas L, Arnon Z, Ziv N, Kremer I, Haimov I. The effects of music relaxation and muscle relaxation techniques on sleep quality and emotional measures among individuals with posttraumatic stress disorder. Mental illness. 2012 Jul 26;4(2).

[DOI:10.4081/mi.2012.e13] [PMID] [PMCID]

42. Saeedi M, ashktorab T, SHAMSIKHANI S, saatchi K. The effect of progressive muscle relaxation on insomnia severity of hemodialysis patients.

43. Jalal manesh S-o-m, zargarani $\mathrm{f}$.

Effectsofprogressivemusclerelaxationtechniqueonfatiguean dsleepquality in patientswithmultiplesclerosis 2015; 23 (3). 44. Dayapoğlu N, Tan M. Evaluation of the effect of progressive relaxation exercises on fatigue and sleep quality in patients with multiple sclerosis. The Journal of

Alternative and Complementary Medicine. 2012 Oct

1;18(10):983-7. [DOI:10.1089/acm.2011.0390] [PMID] [PMCID]

45. Matthews EE. Sleep disturbances and fatigue in critically ill patients. AACN advanced critical care. 2011 Jul;22(3):204-24. [DOI:10.1097/NCI.0b013e31822052cb] [PMID] [PMCID]

46. Parsa Yekta ZP, Sadeghian FM, Taghavi Larijani TP, Mehran AM. The Comparison of Two Types of Relaxation Techniques on Postoperative State Anxiety in Candidates for The Mastectomy Surgery: A Randomized Controlled Clinical Trial. International journal of community based nursing and midwifery 2017; 5 (1): 61-69.

47. Abbasi M, Salemi S, Fatemi Ns, Hosseini F. Hypertensive Patients, Their Compliance Level And Its'relation To Their
Health Beliefs. Iran Journal Of Nursing. 2005 Mar;18(41):61-8.

48. Liu H, Ji F, Peng K, Applegate RL, Fleming N. Sedation after cardiac surgery: Is one drug better than another?. Anesthesia \& Analgesia. 2017 Apr 1;124(4):1061-70. [DOI:10.1213/ANE.0000000000001588] [PMID]

49. Glass J, Lanctôt KL, Herrmann N, Sproule BA, Busto UE. Sedative hypnotics in older people with insomnia: metaanalysis of risks and benefits. Bmj. 2005 Nov 17;331(7526):1169. [DOI:10.1136/bmj.38623.768588.47] [PMID] [PMCID]

50. Francoeur RB. Ensuring safe access to medication for palliative care while preventing prescription drug abuse: innovations for American inner cities, rural areas, and communities overwhelmed by addiction. Risk management and healthcare policy. 2011;4:97.

[DOI:10.2147/RMHP.S24068] [PMID] [PMCID]

51. Ng WL, Peeters A, Näslund I, Ottosson J, Johansson K, Marcus C, Shaw JE, Bruze G, Sundström J, Neovius M. Change in use of sleep medications after gastric bypass surgery or intensive lifestyle treatment in adults with obesity. Obesity. 2017 Aug;25(8):1451-9. [DOI:10.1002/oby.21908] [PMID] [PMCID] 